\title{
OLIGARQUIA MUNICIPAL E INTERESES AGRARIOS: ORIHUELA EN LA COYUNTURA SUBSIGUIENTE A LA PESTE DE 1648
}

\section{Por David BERNABE}

Universidad de Alicante

El concepto de decadencia aplicado a la economía del Seiscientos requiere de una serie de matizaciones que, partiendo de estudios monográficos o de carácter comarcal, revelen o cuestionen en su justo término el significado real de dicho concepto. En este sentido, y por lo que concierne a la agricultura del País Valenciano, las investigaciones llevadas a cabo por James Casey constituyen un punto de referencia inexcusable al plantear el alcance de la crisis, ya no sólo en su concepto cronológico, sino sobre todo en relación con el comportamiento de los distintos grupos que integran la sociedad de la época. Así, ciertos indicios le permitieron detectar un proceso que acabaría por enfrentar a una minoría dinámica de empresarios agrícolas que invertían en la tierra frente a una oligarquía empobrecida, reticente o cualquier innovación por temor a perder su monopolio (1). Tal argumentación parece descansar en un cierto espíritu de empresa atribuido a aquellos individuos que supieron aprovechar las dificultades económicas del resto de sus congéneres, pero no parece clarificar qué tipos de modelos de crecimiento entraban en contradicción. Porque, al mismo tiempo, señala la formación de una clase de ricos labradores que, paulatinamente, entrarían

(1) J. CASEY: «Irrigació i economia al País Valencià. 1589-1680». I Congreso de Historia del País Valenciano, vol. III, Valencia, 1975, pp. 281-289. 
a formar parte de las oligarquías municipales haciendo causa común con ella (2).

Pedro Ruiz, en sus estudios sobre el Señorío de Elche, propone, por otra parte, un enfrentamiento de intereses - que refleja dos vías contrapuestas de transición al capitalismo- entre la pequeña producción campesina de subsistencias, amparada por las reglamentaciones municipales forales, y los grandes propietarios y comerciantes que propugnaban la libre comercialización de los excedentes agrarios (3). Cabría plantearse, no obstante, hasta qué punto la estructura político-administrativa de los municipios valencianos en la época foral respondian realmente a los intereses del pequeño campesinado o si se limitaba más bien a propiciar un cierto paternalismo no exento de la más cruda evidencia respecto al mantenimiento de situaciones de privilegio para la oligarquía local, que ésta supo aprovechar en beneficio propio.

Conocer la dinámica interna de los grupos de poder municipales y sus comportamientos políticos y económicos resulta, pues, imprescindible para la justa comprensión del problema. Prescindiendo por el momento de realizar esta tarea de una manera exhaustiva, aquí se tratará de relacionar de alguna manera la situación de la agricultura en Orihuela y los problemas que de ella derivan con los intereses de la oligarquía local en los años subsiguientes a la epidemia de 1648 . Esto es, en un momento coyuntural un tanto especial pero que, pese a sus graves connotaciones demográficas, más que constituir un corte brusco en la evolución de la Centuria, ha de contemplarse como la culminación de un proceso donde llegan a explicarse de forma más intensa los problemas de fondo. Los intentos del municipio para hacer navegable el Segura y construir un puerto en su costa marítima - constituye una clara muestra - pero sólo una más- de cuáles eran los intereses que se perseguian y qué era lo que se intentaba evitar.

Ciudad de jurisdicción real, Orihuela era la segunda en importancia después de la capital del Reino. Ubicada en el corazón de una fértil huerta bañada por el Segura, constituía la capital administrativa de la Gobernación que se extendía al Sur de Jijona (4), condición que compartía con la de sede episcopal y universitaria.

(2) J. CASEY: «Tierra y sociedad en Castellón de la Plana. 1608-1702», Estudis, n. ${ }^{\circ} 7$, 1980, pp. 13-46, especialmente pp. 35-37.

(3) P. RUIZ TORRES: «Fuerzas productivas y producción agraria en el País Valenciano: crecimiento y crisis en el campo de Elche (1730-1850), Estudis, n. ${ }^{\circ} 7,1980$, pp. 61-110, especialmente pp. 84 y 55 .

(4) Su titular, «el Portantveus de General Governador desa Xexona a esta part», dependía directamente de la Real Audiencia y no del Gobernador General de Valencia, al que estaban subordinados los otros dos, de Xátiva y La Plana. Vid. J. REGLA y R. GARCIA CARCEL: De las Germanias a la Nova Planta, vol. III de Historia del País Valencià. 
Pese a la amplitud y riqueza potencial de sus términos jurisdiccionales para la explotación agrícola - donde, al decir de Escolano, «anda allí tan pródiga la naturaleza, que no hay fruto que se le haya negado» (5) - los recursos demográficos disponibles se mostraron siempre insuficientes, circunstancia no atribuible exclusivamente a la incidencia de la población morisca comarcal (6), puesto que ya antes se había manifestado reiteradamente (7). Una población, pues, no tan densa como se ha querido ver (8), -en 1646 el censo oficial rectificado contabiliza 1.673 casas (9), mientras que los de 1580,1584 Y 1587 sobrepasaban las 2.000 (10) - pero concentrada en el núcleo urbano (11), que la epidemia de 1648 iba a reducir decisiva y drásticamente a porcentajes probablemente cercanos al $50 \%$. Las cifras oficiales hablaban de 5.000 muertos (12) pero, cuestionando su veracidad, es evidente que se trató de una de las ciudades más gravemente afectadas en todo el País Valenciano.

Una primera e inevitable impresión al examinar la documentación de los años inmediatamente posteriores a 1648 conduce a sobrevalorar las nefastas consecuencias del drástico descenso demográfico, puesto que todos los males que padecía la Ciudad eran atribuidos a la despoblación. No se trata de negar la decisiva incidencia que tal catástrofe demográfica y sus secuelas de todo tipo tuvieron en la vida económica de la Ciudad -y particularmente por lo que respecta a la agricultura - pero acudiendo a la documentación anterior a dicho año se llega a sospechar que, en el fondo, la epidemia no hizo sino agravar problemas latentes anteriores hasta límites in-

(5) G. ESCOLANO: Década Primera de la historia de Valencia, libro VI, Valencia, 1610-1972, cap. III.

(6) Aunque las casas moriscas de Orihuela eran sólo 30 en 1597 (J. B. VILAR: «Los moriscos de la Gobernación y Obispado de Orihuela», Al-Andalus, vol. XLIII, 1978, p. 334), la ciudad se quejaba en 1609 de la continua salida de vecinos para ocupar las tierras que habían dejado los expulsos de Albatera, Cox, La Granja y Redován, todos ellos lugares de señorío con población morisca. AMO: Contestador 1609, f. 489 v. Carta de la Ciudad al Virrey (5-X-1609).

(7) He intentado mostrar esto en «Orihuela y los moriscos en vísperas de su expulsión». Revista de moros y Cristianos, Orihuela, 1981.

(8) L. GARCIA BALLESTER y J. M. MAYER BENITEZ en su artículo «Aproximación a la historia social de la peste de Orihuela de 1648", Medicina Española, n. ${ }^{\circ} 65,1971$, pp. 325-326, atribuyen los estragos de la epidemia en Orihuela y su comarca a su gran densidad de población, al no verse gravemente afectada por la expulsión de los moriscos.

(9) AMO: Contestador 1646, ff. 361-361 v. Carta de la Ciudad a Antonio Ortiz, 24-X-1646. El notario, sin embargo, había certificado descuidadamente 1.596 casas.

(10) L. GARCIA BALLESTER y J. M. MAYER BENITEZ: Op. cit. p. 325.

(11) Vid. J. MILLAN: «La Ciudad y los Señores. La crisis del realengo foral en el Sur del País Valenciano». Estudios d'Historia Contemporánea del País Valencià, n. ${ }^{\circ}$ 2, 1980, p. 78.

(12) L. GARCIA BALLESTER y J. M. MAYER BENITEZ: Op. cit. p. 325. 
sostenibles. De este modo, una coyuntura particularmente adversa sacaba a relucir una situación estructural.

\section{EL CONTROL DEL PODER MUNICIPAL}

El régimen foral del municipio oriolano durante el siglo XVIII fue objeto de repetidas modificaciones. Hasta 1625 la Ciudad se regía -mención aparte de Privilegios y Ordenes Reales emanados circunstancialmente en ocasiones diversas a lo largo de toda la época foral- por los estatutos contenidos en el llamado Privilegi del Nou Regiment, otorgado en 1568 (13). En 1625 el Dr. Onofrio Bartolomeo Guinart, por entonces Abogado Patrimonial y Fiscal de la Audiencia de Valencia, añadía una serie de 130 capítulos (14) que llegaron a constituir, junto a los anteriores, el marco legal básico durante toda la Centuria. Pero en 1650-51 - fecha muy significativael Visitador Real D. Antonio Juan de Centelles modificaba e introducía nuevas ordenanzas (15) que, en 1667 , volvían a sufrir nueva revisión, esta vez por obra de D. Luis García de Espejo (16). De esta forma se iba configurando paulatinamente el corpus jurídico para la óptima administración y gobierno del municipio, adecuando los estatutos a las necesidades nuevamente surgidas pero, sobre todo, tratando de impedir la corrupción y el desorden administrativo protagonizados por los encargados de su observancia, como se expresaba explícitamente en las sucesivas reformas. Sin entrar de lleno en un análisis pormenorizado de la evolución del régimen estatutario foral y del sistema financiero municipal, quizás resulte clarificador destacar muy brevemente algunos aspectos en relación con el tema que aquí interesa.

El gobierno de la ciudad de Orihuela corría a cargo de un Justicia Civil, otro Criminal y 5 Jurados, oficios que eran sorteados anualmente por insaculación de las bolsas correspondientes al estamento Militar -integrado por Caballeros no Nobles-y al Real, constituido por Ciudadanos honrados o de Mano Mayor declarados como tales por sentencia de la Real Audiencia con votos del Consejo Supremo de Aragón. El Consejo

(13) Fue dado por Felipe II, en Aranjuez, a 23-XI-1568. AMO: Reals estatuts per a el bon Govern de la ciutat de Oriola (copia de los estatutos de Guinart de 1625 , realizada en 1646), f. $1 \mathrm{v}$.

(14) Firmados en Madrid el 21-XII-1625 y preconizados en la plaza mayor de Orihuela el 8-II-1626. AMO: Ibidem, ff. 28-28 v.

(15) Fueron realizadas en fechas sucesivas (18-VIII-1650, 20-XII-1650, 6-III-1651). AMO: Recopilación de los Estatutos, Privilegios y otras Reales Ordenes dadas a la muy Noble y a la muy Leal Ciudad de Orihuela para su Govierno compuesta de orden de los Ilustres Señores Justicia, y Jurados, y Consejo General de la dicha muy Noble y muy Leal Ciudad, y dedicada a la misma por el doctor Thomas Martínez, Imp. en Orihuela, 1703.

(16) Por entonces ocupaba el cargo de Asesor Ordinario de la Gobernación de Orihuela, Juez de Residencia y Real Visitador. Recibio comisión real a 7-V-1667. AMO: Ibidem. 
General lo componían 40 individuos extraídos asimismo por sorteo anual - una vez adjudicados los oficios de gobierno- entre los restantes insaculados en la siguiente proporción: 16 de la bolsa de los Caballeros, 16 de la de Ciudadanos de Mano Mayor y 8 de la de Ciudadanos de Mano Menor. El Consejo era convocado a instancias de los Jurados para tratar asuntos importantes, pero no constituía una asamblea popular representativa porque sus integrantes pertenecían a la pequeña nobleza local, estando excluidos del acceso a esta condición todos aquellos que habían ejercido por sí, o sus ascendientes, oficios mecánicos o habían trabajado por sus manos. Cargos de carácter administrativo como el Clavario, Camarero o administrador del Pósito, Racional, Almotacén, Obrero, o de cualquier otro tipo como el Síndico, Asesor, Abogado de la Ciudad, etc., podían ser extraídos de las bolsas, nombrados directamente por el Consell en votación secreta o designado por el Rey a propuesta de la Ciudad según el oficio en cuestión.

Condiciones imprescindibles para ser insaculados en cualquiera de las tres bolsas y, por tanto, poder concurrir al sorteo de oficios y consejeros eran, entre otras, disponer de propiedades inmuebles valoradas por encima de las 2.000 libras y poseer caballo propio. Asimismo, estaban impedidos de ejercer cargos públicos los deudores a la Ciudad o al Real Patrimonio, los arrendadores de bienes y derechos de propios, los que ya ejercían algún otro oficio, etc. La graduación o decisión para ser admitido en cualquiera de las tres bolsas correspondía a una comisión de 16 Consejeros -8 Caballeros y 8 Ciudadanos de Mano Mayor - extraídos por sorteo y era realizada cada tres años. Ocho votos a favor eran suficientes para que el candidato pudiese ser graduado e incluido en la bolsa correnpondiente.

En realidad, mediante el sistema esbozado, al tiempo que se reservaban todos los cargos públicos, incluido el Consejo General, para la pequeña nobleza de Caballeros y Ciudadanos, se propiciaba su cohesión interna y su hermetismo, siempre que no surgieran facciones en su seno. Teóricamente, la clase política debía ser lo bastante homogénea como para evitar fricciones de gravedad entre Jurados y Consejo, al poder optar todos y cada uno de los insaculados a la casi totalidad de los cargos sorteados. Por ello el Consejo de Orihuela difícilmente podía asumir funciones de carácter reivindicativo como en otras ciudades del País Valenciano durante la época foral (17). De otra parte, las amplias atribuciones que el régimen foral valenciano otorgaba al poder municipal, acaparado por una oligarquía de privilegiados, propiciaba su utilización para cometer toda clase de abusos e incumplimientos en provecho propio. Y en este sentido hay que valorar la

(17) En Valencia o en Oliva, por ejemplo, donde su composición no era enteramente oligárquica. Vid. J. CASEY: «La crisi general del segle XVII a Valencia (1646-1648)». Boletín de la Sociedad Castellonense de Cultura, t. XLVI, vol. II, 1970, pp. 95-173; F. PONS FUSTER: Aspectos económico-sociales del Condado de Oliva (1500-1750), Ayuntamiento de Oliva, Valencia, 1981, pp. 183 y ss. En Castellón, sin embargo, tenía un carácter similar al de Orihuela. Vid. J. CASEY: "Tierra y sociedad...», p. 35. 
reforma astatutaria de 1624 en que su relizador, el Dr. Guinart, solía encabezar muchas de las nuevas disposiciones con expresiones como la siguiente: «...per quant per experiencia se ha vist lo gran dany que se ha causat y pateix hui en dia la present ciutat y comu de aquella per la mala administracio que y a hagut...» (18). Efectivamente, no debió ser muy del agrado de la oligarquía local las innovaciones introducidas puesto que 20 años más tarde llegaron a manifestar:

«Quando el Sr. Guinart estuvo en esta Ciudad era ei tiempo florido en que todos los cavalleros y ciudadanos querian governar en ella y lo tenian a mucha dicha, pues nos hizo tanta merced con 133 estatutos que nos dexo que no solo los que avian se saiieron del govierno, pero no quiere entrar nadie despues aca, y assi no tiene que maraviliarse de que ay tantos consexeros que dispensar pues ninguno de ellos quiere insacularse" (19).

Y en un memorial enviado al Rey la Ciudad recordaba cómo en las Cortes Generales de 1645 el Síndico de Orihuela había solicitado la reformá de algunos estatutos, sin que se diera complimiento a la petición (20). La tan ansiada reforma llegó finalmente en 1650-51, pero sus efectos no fueron en manera alguna los esperados por la élite dirigente. En primer lugar, y tras revisar los libros de cuentas municipales, el Real Visitador hizo las condenas oportunas obligando a los responsables de la administración al pago de los alcances en que habían incurrido (21). De los 11 Caballeros insaculados, 7 resultaron condenados como deudores con motivo de la inspección, renunciando 6 de ellos a la insaculación; y otro tanto ocurrió con los Ciudadanos de Mano Mayor (22). Entre otras medidas adoptadas, Centelles introdujo innovaciones importantes en el sisterna de administración del Pósito «per quant la administracio dels forments de la Cambra eo posit de la present Ciutat es la de mes importancia, y en la que la Ciutat te major parjuhi, e conve al benefici publich millorar aquella, y prevenir inconvenients» (23), suprimió algunos oficios menores por considerarlos innecesarios, redujo los salarios de otros y modificó el mecanjsmo de financiación municipal agilizando las transferencias de pagos entre los distintos bloques consignados para tales efectos (24).

(18) AMO: Recopilación... f. 82.

(19) AMO: Contestador 1646, f. 299. Carta de la Ciudad a Vicente Sánchez de Castellar (10-II-1646).

(20) Ibidem, ff. 311 v.-312, Memorial de la Ciudad al Rey.

(21) Aún no disponiendo del libro de cuentas realizado a efectos de la Visita, los documentos ser̃alan la cifra de 14.368 libras y 6 dineros de alcances. (AMO: Contestador 1652, f. 405) y 4.191 libras, 1 sueldo y 6 dineros por condenas criminales (AMO: Contestador 1654, f. 328).

(22) AMO: Contestador 1651, ff. 373-374 v, La Ciudad al Virrey (21-12-1650).

(23) AMO: Recopilación..., f. 84.

(24) Vid. los estatutos de 6-III-1651, en AMO: Ordenes Reales 1650-1652, ff. 37 y ss. 
En definitiva, la reforma administrativa de Centelles pretendía una mayor claridad y control de las cuentas y balance de las finanzas municipales (25), lo que no debió conformar satisfactoriamente a sus responsables, que optaron por salir de las bolsas agravando aún más la situación descrita por la Ciudad con ocasión de la reforma de Guinart. Porque la constante falta de insaculados no era ninguna ficción más o menos interesada, sino una realidad repetida año tras año y agravada, sobre todo, por la actitud de los Caballeros, como muestran las cifras siguientes (26):

\section{INDIVIDUOS INSACULADOS EN LAS DOS PRIMERAS BOLSAS}

$\begin{array}{lrrrrrrrrrrrr}\text { Caballeros } & 10 & 9 & 10 & 9 & 8 & 6 & 6 & 5 & 5 & ? & 5 & 5 \\ \text { Ciud. Mayor } & 18 & 18 & 24 & 13 & 17 & 13 & 12 & 8 & 8 & ? & 10 & 10\end{array}$

Si gran parte de la élite se negaba a entrar en las bolsas, los numerosos impedimentos que asistían a los ya insaculados determinaba que, en muchas ocasiones, no pudieran siquiera proveerse normalmente los oficios, cuya extracción se efectuaba en primer lugar. En todo caso, una vez éstos habían sido sorteados, apenas quedaban insaculados para la extracción de Consejeros. Entonces, la Ciudad elaboraba una lista de Caballeros y Ciudadanos, tanto insaculados como no insaculados, con sus impedimentos correspondientes, en número doble al de Consejeros vacantes en cada bolsa y la remitía al Virrey para que éste los nombrase. Normalmente el Virrey solía designar a los no insaculados que carecían de impedimentos, prefiriendo a veces dejar incompleto el cupo de los 40 Consejeros antes que dispensar de sus impedimentos a los insaculados, sobre todo si éstos ejercían ya algún oficio o eran deudores a la Ciudad, lo que ocasionaba las correspondientes protestas (27).

(25) «...per a que en cada any averigue la Ciutat per medi del Racional tot les contes de ses rendes ab claritat y major facilitat». AMO: Ibidem, ff. 25 y ss.

(26) Datos extraídos de los Contestadores referentes a los años señalados. La bolsa de ciudadanos de Mano Menor solía estar mejor surtida en relación a los oficios extraídos de ella, por lo que no of recía graves problemas. De todas formas, una vez efectuados los sorteos apenas quedaba alguno sin cargo.

No hay contradicción entre las cifras de 1650 y la afirmación anterior sobre las renuncias a la insaculación que tuvieron lugar en 1651. El hecho se explica -como hemos tenido ocasión de comprobar - porque en mayo de 1650 se insacularon varios individuos merced a la graduación realizada por entonces, tal y como debía verificarse cada tres años. Los nuevos insaculados no aparecen incluidos en las bolsas de 1650 al ser éstas reconocidas para los sorteos a principios de año, pero sí en la de 1651, cuando algunos expresaron su renuncia.

(27) Ello ocurrió, por ejemplo, en 1653, cuando el Virrey, que debía designar para consejeros ese año a 15 Caballeros, 15 Ciudadanos de Mano Mayor y 2 de Mano Menor, sólo nombró a los que carecían de Impedimentos, faltando 14 consejeros -7 por cada una de las dos primeras bolsas- para completar los 40. AMO: Contestador 1653, f. $211 \mathrm{v}$. La Ciudad al Virrey (14-1-1653). 
Algo distinto era el criterio seguido para la nominación de cargos como Justicia Civil, Justicia Criminal, Jurados, Camarero, Clavario, Almotacén y Obrero, cuando en el sorteo efectuado de las bolsas correpondientes, no habian podido se adjudicados en su totalidad por estar impedidos los insaculados. En este caso el Virrey dispensaba de los impedimentos pero no debía, conforme estatutos de Orihuela, designar a quien no hubiera entrado en las bolsas.

Durante el último año de Virreinado del Conde de Oropesa, sin embargo, se introdujo la práctica de nombrar a los no insaculados (28) y como la Real Audiencia resolviera en 1650 proseguir dicha innovación, la Ciudad protestó por atentar contra sus privilegios. Uno de sus abogados en Valencia, al recibir instrucciones para tratar estos asuntos, reconocía la razón que asistía al Virrey: «... que si su Exa. (el Virrey) hiziesse eleccion de los insaculados impedidos no tratarian nunca de quitar el impedimento lo que resultaria contra el bien publico» (29). Y esto era precisamente lo que pretendía cierta élite de la Ciudad: seguir ocupando sus cargos - a veces acumulando varios en una sóla persona - sin tener que dar cuenta -o hacer definiciones- de oficios anteriores ni pagar sus deudas al erario municipal, pues eran éstos los impedimentos más frecuentes.

Si a esta decisión de la Real Audiencia añadimos los efectos de la Visita de Centelles, del mismo año, se comprenderá fácilmente la deserción del gobierno y la administración local, pues nada separaba ya la condición de insaculado de los que no lo estaban para acceder a cualquier cargo. Como la situación se agravaba, el Virrey hubo de intervenir a instancias del Procurador Patrimonial prohibiendo a los Jurados de Orihuela permitir la salida de las bolsas y exigiendo, en un plazo de seis días, explicaciones a todos aquellos que lo habían hecho a partir de 1640 «porque de muchos años a esta parte siempre que qualesquier insaculado se a querido salir lo a echo» (30). En 1654 aún se mantenía prácticamente el mismo número de insaculados, y como nada hacía prever que éste pudiera incrementarse, la Ciudad solicitaba al Rey facultad para que los Nobles pudieran insacularse en la bolsa de los Caballeros (31) - lo que obtuvo en 1656 (32) - al tiempo

(28) AMO: Ordenes Reales 1650-1652, ff. 64-71, Memorial de la Ciudad al Virrey (VI-1651).

(29) AMO: Ibidem, ff. 62-63 v. El Dr. Claudio Bertina a la Ciudad (22-VI-1651).

(30) AMO: Contestador 1652, ff. 345 v-346, La Ciudad a Centelles (9-III-1652).

(31) «...y que los nobles que fueran insaculados no puedan pretender precedencia alguna a officio que al militar le toque». AMO: Contestador 1654, ff. 261 v-262, Memorial de la Ciudad al Rey (9-III-1654).

(32) Provisión real fechada en Madrid, a 21-III-1656. Los Nobles serán insaculados por el Rey en la bolsa de los Caballeros proponiendo sujetos la Ciudad. AMO: Recopilación..., ff. 12-13. En la ciudad de Valencia la insaculación de los Nobles para los oficios mayores databa de 1651 . Vid. L. J. GUIA MARIN: «Los estamentos valencianos y el Duque de Montalbo: los inicios de la reaccion foral», Estudis, n. ${ }^{\circ} 4,1974$, p. 134, n. 29. 
que exigía nuevos estatutos, pues con los vigentes «...por tener penas tan rigurosas muchas personas se han salido del govierno y otras no han querido entrar a governar» (33).

Todo esto requiere, no obstante, de alguna matizacion. En principio parece ser que los cargos políticos con mayor poder decisorio, como el Jurado, eran más apetecidos que aquellos otros cuyas funciones quedaban relegadas a un nivel puramente administrativo de las finanzas municipales. Tal era el caso del Clavario, Camarero y Racional, por ejemplo. Pero ello ocurría porque dada la caótica situación fínanciera de la Ciudad el ejercicio de tales oficios podía llegar a ser contraproducente para sus beneficiarios si no acudían a prácticas fraudulentas. Algunos de los insaculados -que habían permanecido como tales para poder optar al cargo de Consejero-, si habían sido agraciados en el sorteo para uno de aquellos oficios, se inhabilitaban voluntariamente «escusándose con que no tienen fiadores» (34), condición que era imprescindible para su provisión. Había incluso quienes huían de la Ciudad por temor a las penas que podrían seguírseles si renunciaban. Otra de las formas de permanecer insaculado e impedido a la vez era prescindir de hacer el alardo de caballo exigido. De este modo, cabía la posibilidad - con los Virreyes anteriores a Oropesa- de ser nombrado Jurado, mientras que para aludir otros oficios siempre quedaba el recurso de no presentar fianzas.

Si el constante y creciente endeudamiento de la Ciudad provocaba situaciones de rechazo para los cargos de administraciones públicas, no menos importante era la consideración de los bajos salarios percibidos por su ejercicio en relación a los riesgos que este podia comportar (35). Mención aparte de los gastos que suponian las contínuas levas y servicios a la Monarquía, tanto de carácter ordinario como extraordinario, la ineficaz administración de las rentas municipales y los fraudes cometidos por los encargados de su gestión habían sumido a la Ciudad en un situación de completa

(33) AMO: Contestador 1656, f. 348 v. Instrucciones de la Ciudad para el Dr. Pedro Díaz de Salazar.

(34) Tales prácticas, denunciadas ya en 1642, determinaron que los Virreyes tuviesen que imponer penas a aquellos que renunciaran a ejercer sus oficios. AMO: Contestador 1643, f. 197. Memorial del Síndico de la Ciudad al Virrey, datado de 1642.

(35) En 1642 ser solicitaba del Virrey un aumenio de salario para el Clavario, pues «por ser tan limitado respeto del mucho trabaxo del oficio ninguno de los insaculados le quiere servir escusándose con que no tienen fiadores». El memorial en cuestión pretendía se igualase al asignado al Camarero, consistente el 150 libras anuales, porque «quando se le señaló por salario al oficio de clavario 75 libras fue quando aquella ciudad no tenía la mitad de las deudas que pagar que tiene hoy». AMO: Ibidem, ff. 197-197 v (1642).

Otro ejemplo: en 1650 el Rey había incrementado el salario del Racional de 100 a 150 libras anuales, pues «por tener tan poco salario ninguno a petesido dicho oficio y a muchos años que esta vacio». Pese a ello, la Ciudad no tenía reparo en manifestar: «Y tenemos por cierto que aún con dichas siento y sinquenta libras no a de ver quien lo apetesca». AMO: Contestador 1650, f. 338, La Ciudad a Gavino (25-X-1650). 
bancarrota, pese a que los presupuestos anuales debían producir en teoría un superávit. Algunos datos al respecto pueden resultar ilustrativos: en 1652 y 1654, por ejemplo, las rentas de la Ciudad ascendian a 18.393 y 14.710 libras respectivamente, de las cuales quedaban consignadas para pagos de salarios, pensiones de censales y otras obligaciones diversas $16.780 \mathrm{y}$ 11.710 libras, lo que debía arrojar un saldo positivo de 1.613 y 2.405 libras respectivamente (36). Pero los balances siempre resultaban deficitarios y las quejas sobre el endeudamiento perenne de la Ciudad no dejaban de prodigarse una y otra vez.

Dada la imposibilidad de hacer frente al pago de las pensiones adeudadas por censales impuestos por el municipio con cargo a las rentas de la Ciudad (37), en 1650 se convocó una junta de censalistas acreedores en la Cofrafía de S. Jaime de la ciudad de Valencia, donde asisítió el Síndico de Orihuela, llevando certificados del estado de las rentas de la Ciudad, para tratar conjuntamente las medidas pertinentes y evitar los apremios por impagos. El Síndico manifestaba que a la Ciudad «le faltan más de tres mil libras cada año para pagar los censos y sin esto que devia mas de veinte mil ducados de lo que se gasto en el tiempo de la peste, de rehagos de pensiones y otras deudas y que por la imposibilidad dexaba de pagar enteramente los censos» (38). Al año siguiente, las deudas y atrasos a los censalistas ascendían a 7.506 libras (39).

Algunos de los acreedores asistentes a dicha Junta desestimaron, no obstante, las pretenciones de la Ciudad en razón, según el Marqués de Oroni - apoyado por el Colegio de Predicadores de Orihuela, que suscribio enteramente su determinación-. de que las rentas sobrepasaban con creces las 10.000 Libras y «...que los gastos y salarios que se ponian tenia eran excesivos y que se debian regular». El procurador del Cabildo Catedralicio de la Ciudad, también presente como acreedor y mejor conocedor de las finanzas municipales y de su gestión, fue sin embargo mucho más lejos al denunciar públicamente «...que los del govierno se quedavan con muchas cantidades». También Centelles coincidia con la apreciación de los acree-

(36) AMO: Clavería 1652 y Clavería 1654.

(37) El Colegio de Predicadores de Orihuela Constituía la principal entidad acreedora de la Ciudad, a quien debia responderle por pensiones de censales 1.447 libras y 5 sueldos anuales. AMO: Contestador 1652, La Ciudad a Francisco Córdova, f. 416 v. En 1649 las relaciones entre ambos atravesaron momentos difíciles, al conseguir el Colegio la derogación de una concesión real a la Ciudad por la que se le daba facultad para suspender momentáneamente los pagos de las pensiones. AMO: Contestador 1649, ff. 512 v-513, 522, 522-523 v, 537-537 v...

(38) AMO: Contestador 1650, f. 370, el Dr. Bernardino a la Cjudad, 17-III-1650.

(39) AMO: Contestador 1651, f. 379 v, La Ciudad al Rey (3-III-1651). 
dores sobre las suficiencias de las rentas de la Ciudad para hacer frente a sus pagos, tras haber examinado detenidamente sus cuentas (40).

Malversación de fondos públicos, gastos superfluos excesivos... A todo ello habría que añadir el impago de las deudas contraídas por los arrendadores de propios (41) y la negativa a dar cuentas de las administraciones ejercidas, como, efectivamente se objetaba a gran parte de los insaculados como motivo de impedimento para ser sorteado en los nuevos oficios. El miedo a no obtener suficiente beneficio de tales administraciones en unas circunstancias en que la situación financiera se deterioraba cada vez más no impedía, sin embargo, que algunos se esforzaran por acaparar varios cargos (42) o sucederse en el mismo una vez acabado su mandato (43).

(40) «Per quant havent fet lo tanteo y valans de les Rentes y entrades de la present Ciutat y dels carrechs y responsions de aquella nos ha constat tenir la Ciutat suficient renta y entrada per a poder pagar ab itegro les pensions dels censals que fan suma cascun any de 4.566 lliures y 16 dines (...) y de no pagarles ab puntualitat la Ciutat se han seguit molts gastos y despeses de execusions com en lo discurs de la visita se a averiguat». AMO: Ordenes Reales 1650-1652, f. 37.

41) Esta afirmación se puede constatar consultando los libros de Clavaría de los años a que nos referimos. No deja de ser sintomático, por otra parte, que entre tales arrendadores que se negaban a pagar se encontrasen varios Caballeros y Ciudadanos locales. La justicia debía intervenir cuando ello ocurría embargando los bienes muebles que encontraran en las casas de los deudores y, si éstos no eran suficientes, llevándolos a prisión hasta que pagasen. Pero los alguaciles encargados de su apresamiento debieron inhibirse frecuentemente de cumplir sus obligaciones. Así, de los 21 deudores sobre los que pesaban orden de arresto en 1650 por esta causa, el alguacil declaraba no haber apresado a ninguno de ellos por no haberlos encontrado. AMO: Clavería 1649 (sin foliar).

(42) En 1655, en carta al Virrey, la Ciudad «aviendo entendido las muchas diligencias, que con muchos medios hasen algunas personas, para que $V$. Exa. les dispense en los impedimentos que padecen para poder concurrir a los oficios del govierno de esta Ciudad, y en particular los que exercen un officio para tener otro», pedia «que los officios de su govierno les ocupen cada huno un sujeto, pues les ay en la Ciudad dignos de la merced». AMO: Contestador 1655, ff. 221 v-222.

(43) Un caso interesante, a este respecto, es el protagonizado por el Caballero Juan Soler de Cornellá, quien, en 1646, ejercía el cargo de Camarero del pósito. Pese a que, según estatutos, dicho oficio era sorteado anualmente de forma alternativa de la bolsa de los Caballeros y de la de Ciudadanos de Mano Mayor, una vez acabado su mandato llegó a un acuerdo con el nuevo administrador para que, buscándole aquél fiadores; le dejara continuar en el cargo. La Ciudad protestó al Virrey, puesto que de ello «se an de seguir muchos inconvenientes pues la quenta y entriega del dinero no será real y efectiva según debe ser» (AMO: Contestador 1646, ff. 322-322 v). El intento quedó frustrado y el oficio de camarero fue encomendado a una tercera persona (AMO: Ibidem, f. 325 v). Pero dicho Soler de Cornellá volvió, esta vez con éxito, a ejercer la administración del pósito en los años sucesivos de 1648 y 1649, «per que en la encomanda de dit offissi solo se ha tengut considerasio a que la persona sia expedient y habil y no a que toque als Jurats dels estament alternativament» (AMO: Contestador 1650, f. 53). Por lo visto se había olvidado ya que durante el tiempo en que ejerció el cargo, en 1646, Soler de Cornellá fue acusado de haber comprado trigo para el pósito $\mathrm{y}$, sin haberlo introducido en él, 10 había vendido directamente a los panaderos, por lo que «a venut mes forment del que per lo llibre de la sua administracio consta haver venut» (AMO: Contestador 1646, ff. $82 v-83$ ). 
En consecuencia, puede hablarse de una agudizacion de la crisis financiera de la ciudad de Orihuela a mediados del siglo XVII, de resultas de la ineficacia y corrupción administrativa protagonizada por la pequeña nobleza en su lucha por su supervivencia como tal, en la cual utiilizaba todos los resortes a su alcance. Su monopolio del poder político y administrativo le aseguraba, de una u otra forma, su control permanente de la situación, aunque aparentemente renunciase a ejercerlo cuando la posibilidad de exprimir al máximo sus ventajas habían llegado a un límite. Pero, por otro lado, estaban sus intereses agrarios, que habian de preservar del modo que fuera y que también se veían gravemente afectados por la deteriorada situación económica general. Todo ello impulsaba a la clase dirigente a no abandonar el poder, puesto que las reglamentaciones forales ponían en sus manos amplias atribuciones que habían de aprovechar. Salir de las bolsas o negarse a ser insaculado no significaba gran cosa pues, al fin y al cabo, no por ello quedaban excluidos de ejercer cargos públicos.

\section{La problemática agrícola}

Aún sin disponer de cifras concretas relativas a la estructura de la propiedad en el término de Orihuela hacia mediados del Seiscientos, es de suponer una elevada concentración en manos de la nobleza superior -con títulos de don- e inferior, integrada por los Caballeros y Ciudadanos que constituían la oligarquía municipal. El límite de las 2.000 libras en bienes raices francos de deudas como una de las condiciones indispensables para poder acceder a la condición de insaculado hacen pensar, efectivamente, en la existencia de propiedades nada despreciables. No sabemos qué sistema de explotación prefería esta clase dirigente pero, junto al arrendamiento a corto término, la explotación directa mediante la contratación de trabajo asalariado debió estar bastante difundida. En 1646, por ejemplo, la Ciudad se excusaba de no haber «..podido juntar el Consejo por el tiempo tan ocupado de las bendimias») (44), lo que parece indicar que los Consejeros se trasladaban a sus casas de campo para supervisar de cerca las labores del personal empleado.

Frente a éstos, la mayor parte de la población dedicada al sector agrario debía vivir en condiciones de suma pobreza, bien como jornaleros, bien como campesinos apenas autosuficientes. En 1645 la Ciudad manifestaba al Virrey las enormes dificultades que atravesaban sus vecinos con ocasión de una orden para el alojamiento de tropas, pero no negaba la diferencia social existente, aludiendo a «..la pobreza de los vezinos de esta Ciudad que estan que no nos atrevemos a que se aloxen en sus casas porque no lo an de poder llevar i si queremos que esten en casa de los cavalleros y ciuda-

(44) AMO: Contestador 1646, f, 344 v. La Ciudad a Bartolmé Cascante (18-IX-1646). 
danus demas de por ser i consistir su vivir en la labrança..» (45). Por otro laco, el sistema fiscal basado en la imposición de sisas municipales a los productos básicos de consumo como el pan, la carne, el vino y el pescado incidía en una paulatina acentuación de la polarización social, al recaer de forma más giavosa sobre aquellos sectores no autosuficientes: «..porque un labrador que tiene en su cassa quatro o seis personas, pasa el año con pan y vino de su cosecha sin hir a la taverna y si bive en el campo, o, en la huerca sin moler en los molinos de Orihuela, y la carne ia puede tener y criar en cassa, con lo qual no pagaria sissa ninguna en pan, vino, ni carne») (46).

Que la élite dirigente estaba constituida por hacendados parece evidente; más ciudoso es que consiguieran rentabilizar ad̉ecuadamente sus explotaciones. Porque los problemas de productividad agrícola eran graves y complejos. Ia debiilidad de los capicales aplicados a la explotación de la tierra se ciebía en parte a la escasez de numerarario y a las graves hipotecas que pesaban sobre ella, pero, en último término, iba estrechamente ligada a las reducidas posibìlidades de comercialización de los excedentes y a los elevaúos costes de producción. No deja de ser significativo que, en 1655, ante el peligro de que muchas acequias dejaran de mondarse, con las consiguientes perdidas de muchas haciendas, el Consejo determinara cobrar las derramas en trigo, porque de otra forma nadie las pagaría (47). Los que cedian sus haciendas en arrendamiento se quejaban de que «muchos dexan de arrencar por las excesivas mondas, i por no tener caudal para sembrar» (48) y los que deseaban venderlas, de lo «difficultos de trobar qui compre les terres y quant se trove sera esperantlo a pagues o fent carregament de censal» (49). E incluso se llegaba a manifestar "..que muchas tierras de la guerta estan incultas por las gïuesas penciones y muchos cargos que tienen» $(50)$.

Los aitos costes que suponían los trabajos de limpieza de acequias y azarbes para el explotađor directo podían incluso hacer irrentable la explotación en $\in$ seno de una economía atrasada donde las posibilidades de beneficio eran mínimas, por complejas razones estructurales. Y si esto era válido para eì mediano o gran cosechero, tanto más para el pequeño campesino quien, ađeinás, ofrecía menos resistencia al pago de las mondas (51) por

(45) AMO: Contestskor 645 , f. 373. La Ciudad al Virrey \{29-I-1645). Y en 1655 se hablaba del «inombre rico o cavallero que paga oy mondas de mil tahullas». AMO: Provisiones Keailes 1571-1688, f. 192, Memorial sobre mondas al Sr. Obispo.

(45) ANHO: ibuden, f. $192 \mathrm{v}$.

(47) ANIO: Contestador 1655, f. 206, Ajust de Consell (25-I-1655).

(43) AJMO: Provisiones Reales 1571-1688, f. 198, Menorial al Dr. Salazar.

(49) AMO: Contestauior 1646, f. 266. Memorial a la Ciudad.

(50) AMO: Coniestador 1649, f. 542, La Ciudad a D. Luis García de Espejo (28-VII-1649).

(51) De ello se quejaba un memorial enviado a los Jurados en 1652. AMO: Consestador 1652, f. 271 . 
miedo a las ejecuciones judiciales que pudieran seguírsele y ante las cuales había de sentirse más indefenso que el rico (52).

No ha de extrañar, por tanto, que uná institución tan famiîiarizada con la explotación agrícola como el Colegio de Predicadores de Orihuela (53) renunciara, en 1663, a proseguir la explotación de una gran heredad llamada de Mayayo a favor del síndico de la acequia del mismo nombre. Las razones eran bastante explícitas: «..por ser dicha renunciacion en evidente utilidad del Colegio, por los muchos gastos de mondas y derrama que se es ocasiona dicha heredad sin esperanças de ningun provecho» (54). Pero no debió tratarse de un hecho aislado mientras la explotación del terrazgo no permitiera una utilización tal que rindiera un excedente. Así, en 1652, una crida de los Jurados regulaba los salarios de los mondadores porque «..moltes perçones dexen de mondar ses asiendes per ser lo dit gasto tan grau que lo util y fruits que es persibixen de les terres no poden ygualar ab lo gasto» (55). Además, las eventuales inundaciónes que de vez en cuarido asolaban la huerta, como la del 1651, dañaban graveinente los edificios de riego, incrementando los gastos necesarios pará su nueva puesta en funcionamiento (56).

La situación debió llegar a tales extremos que, en 1655, se trató de «..procurar un medio fácil para conseguir que los edificios de la guerta, assi de riego como de avenamiento, se limpien cada ano, en que se juzga consiste la abundancia de frutos, augmento de caudales, i descanso de los vezinos» (57). A tal efecto se presentaron varios proyectos al Concejo y al Obispo sobre el mecanismo a seguir para evitar la imposición de derramas demasiado gravosas. Uno de los memoriales - presentado al Dr Salazar-, tras explicar minuciosamente en qué consistía su propuesta acababa señalando, no sin cierto exceso de optimismo, las ventajas que se seguirían de su aplicación. Su interés radica en que arroja bastante luz sobre los proble-

152) Uno de los memoriales sobre mondas, el dirigido al Sr. Obispo, declaraba «... que oy la total causa de no pagarse las mondas son los que más haziendas tienen y los pobres que tienen pocas son puntuales en pagallas y temen más las execusiones». AMO: Provisiones Reales 1571-1688, f. 192 v.

(53) Vid mi tesis de licenciatura Tierra y Sociedad en el Bajo Segura (1700-1750), Universidad de Alicante, Facultad de Filosofía y Letras, 1980, ff. 157-187 (en prensa).

(54) AHO: Consejos del Colegio desde 12 de febrero de 1652 hasta 31 de enero de 1754, p. 10 .

(55) AMO: Contestador 1652, f, 179. Crida de 30-X-1652.

(56) En carta al Virrey la Ciudad aludía a tal inundación «...que los nasidos no han visto tal (...) de suerte señor que a sido segunda peste (...) y sólo el daño que a echo en las asequias y asarbes y escorredores es innumerable porque se an de sacar de nuevor. AMO: Contestador 1651, f. 411 (18-10-1651).

(57) AMO: Provisiones Reales 1571-1588, f. 196, Memorial al Dr. Salazar. 
mas agrarios de Orihuela, tal como lo sentían los hacendados y cosecheros, y sus intereses económicos, cuyas realizaciones venían siendo frustradas por condiciones adversas:

«La primera que si seexecuta en todas las cequias auran menester tres mil cayces de fondo y en ellos asegura la Ciudad seis mil barchillas de compra para su posito que seran 500 cayzes cada año

La segunda augmentarse de valor las tierras, pues el estar francas de mondas, i tener cierta la simiente para sembrar se les dara bondad intrinseca, i augmentara su valor.

La tercera que se hallaran mas arrendadores para las tierras con mas augmento de precio, porque muchos dexan de arrendar por las excesivas mondas, i por no tener caudal para sembrar, y aora tienen asigurado lo uno y lo otro.

La quarta que con esta occasion muchos que labran en el campo porque no pagan mondas, labraran en la guerta si estan francos de ellas por ser mas cierta la cosecha en esta que en aquel.

La quinta que puede ser que muchos forasteros vengan a vivir a esta ciudad porque la abundancia de cosechas la haran mas barata, y estas las conseguiran con menos gasto que antes, y tendran asigurado que no dexaran de sembrar por falta de simiente.

La 6 que las avenidas del rio no causaran tanto daño porque estando limpios los desaguaderos terna el agua su curso mas veloz i desaguara con mas presteza.

La 7 que se excusaran los quexos de agua hurtada porque estando sobrada cada qual terna la que huviese menester sin tocar la del vezino.

La 8 que las tierras perdidas se cultivaran porque si por ellas no se ha de pagar mondas no renunciaran el riego dellas y las procuraran

La 9 que se hallaran mas labradores quinteros que se escusan de serlo por no pagar la mitad de las mondas de agua viva que pagan de lo que siembran.

La ultima sin otras que se pueden traer que mayor utidid se puede considerar, si el rico que no tomara el trigo si que lo aza a otro no pagara un real de mondas y el pobre pagara la mitad te lo que antes sin sentirlo, y terna asigurada su cosecha en el simeils (58).

Incremento del valor de la tierra, abundante oferta reducción de costes de producción, poblamiento y ocupacist se la huerta en detrimento del campo, inmigración, extensión del cultivo, exención del pago de mondas para los ricos; tales eran las felices perpectivas que el autor del proyecto se prometía. No es difícil adivinar, pues, qué grupo social había inspirado su redacción y a qué intereses respondine 348 previsiones. Pero junto a los problemas implícitamente señalados - desvalorización de la

(58) AMO: Ibidem, ff. 198-198v. 
tierra, escasez de arrendatarios, ausencia de capitales, despoblación, elevados costes de producción, daños por inundaciones, robos de agua, etc.que dificultaban, si no obstaculizaban, la rentabilidad de la empresa agrícola, el memorial significaba:

«No dudo que el medio mas efficaz para que las provincias queden enriquecidas, es la abundancia de cosechas; pero la experiencia me persuade a que piense lo contrario en esta ciudad»)

$Y$, a continuación, tras señalar los ínfimos precios a que se vendían las cosechas de trigo, cebada y vino, añadía:

«Luego nuestra perdicion no consiste en tener pocas cosechas, sino en no haver gente que se coma o compre lo que cogemos, i en no tener precio fixo los jornaleros»

He aquí, pues, tres nuevos obstáculos agravados por la atroz despoblación en que había quedado sumida la Ciudad y su comarca como consecuencia de la catástrofe demográfica de 1648. Cuestiones éstas que merecen un análisis más detenido y que revelan hasta qué punto las reglamentaciones y disposiciones municipales que otorgaba el régimen foral podían ser esgrimidas por la clase dirigente para la defensa de sus intereses como cosecheros, a través de un intervencionismo en la vida económica de la Ciudad que podía ser dispensado en beneficio propio cuando las circunstancias así lo aconsejasen.

\section{COMERCIALIZACION E INTERVENCIONISMO MUNICIPAL}

Las disposiciones acerca de la realización de intercambios comerciales con el exterior quedaban enteramente al arbitrio de los Jurados de la Ciudad y, concretamente, en lo que respecta al trigo y al vino. Mientras que el privilegio del vino - concedido por Pedro IV de Aragón en 1383 (59)- tenía como objetivo primordial asegurar a los cosecheros locales la venta de sus cosechas en el interior, evitando la competencia de caldos forasteros de mejor calidad (60), la prơtección al trigo era prácticamente innecesaria. Cuando la producción local era deficitaria, los Jurados y Consejeros concedían las licencias oportunas para la importación de vinos foráneos, encargándose directamente la administración del pósito del abastecimiento triguero. Menos frecuentes eran, sin embargo, las disposiciones prohibitivas de la exportación de ambos productos. En el caso del vino porque, da-

(59) Privilegio dado en Monzón, a 8-X-1383. Por él se prohibía introducir vino en la Ciudad procedente de fuera de sus términos, salvo en caso de urgente necesidad, en cuyo caso el Consejo daría las licencias pertinentes. AMO: Contestador 1657, f. 403. La Ciudad al Obispo (VIII-1657).

(60) También Alicante tenía un privilegio similar con idéntica función. Vid. la tesis doctoral de E. GIMENEZ LOPEZ: Alicante en el siglo XVIII, Universidad de Alicante, Facultad de Filosofía y Letras, 1980, ff. 336 y ss. (en prensa). 
da su pésima calidad (61) y su relativamente débil -o nula- excedencia, no debía contar con una demanda efectiva en el mercado exterior; y sólo una catástrofe climatológica podía determinar la adopción de medidas prohibitivas para el trigo.

En definitiva, la regulación de los intercambios con el exterior gozaba de una gran flexibilidad en razón de la aleatoriedad de las cosechas, cuya cuantía junto a las necesidades impuestas por la demanda interior, aconsejaban las disposiciones del gobierno municipal al respecto. Pero, en primer término, se trataba de asegurar la venta de la producción propia en el mercado local. El aludido privilegio del vino actuaba en este sentido y no muy ajena a estos intereses hay que situar la actuación de los administradores del pósito.

Instituido teóricamente para evitar problemas de abastecimiento y garantizar a la población local el aprovisionamiento del pan y del grano para la siembra, la administración del pósito, ejercida por individuos sorteados alternativamenge de las bolsas de Caballeros y Ciudadanos de Mano Mayor, dejaba mucho que desear. Uno de los proyectos presentados sobre mondas - dirigido al Sr Obispo- manifestaba, como una de las ventajas que se seguirían para el común de ser aceptado, el que

«todos igualmente con proporcion a lo que riegan, y cogen entraran trigo en el posito y no podra quexarse el pueblo de que solo entre tres o cuatro personas llenan el posito, $y$ las demas se quedan sin este beneficio y sin poder despachar el que cogieron porque (...) la Ciudad no puede recibir mas comodidad, de que el trigo de la tierra que compra sea de tres o quatro, que de que sea de todos» (62);

lo que significaba una denuncia de prácticas encaminadas a monopolizar las ventas, en beneficio de una minoría de cosecheros. Y entre los principales vendedores de «cantidades gruessas» el autor del memorial señalaba al

\begin{tabular}{lrrrrrrrr} 
& \multicolumn{1}{c}{$\mathbf{1 6 5 1}$} & \multicolumn{1}{c}{$\mathbf{1 6 5 2}$} & \multicolumn{2}{c}{$\mathbf{1 6 5 5}$} & \multicolumn{2}{c}{ TOTAL } \\
\hline & N. ${ }^{\circ}$ Cantidad & N. ${ }^{\circ}$ & Cantidad & N. ${ }^{\circ}$ Cantidad & \multicolumn{1}{c}{ N. ${ }^{\circ}$ Cantidad } \\
\hline Nobles & 6 & $234-2$ & 3 & $164-9$ & 3 & 87 & 12 & $485-11$ \\
Eclesiásticos & 1 & 10 & 2 & $79-8$ & 4 & $353-3$ & 7 & $442-11$ \\
Pequeria nobleza & 5 & $106-11$ & 8 & $594-2$ & 4 & $204-1$ & 17 & $905-2$ \\
Plebeyos & 7 & $237-8$ & 3 & 83 & 2 & 41 & 12 & $362-7$ \\
\hline TOTAL & 19 & $588-9$ & 16 & $921-7$ & 13 & $686-3$ & 48 & $2.196-7$
\end{tabular}

(Cantidades expresadas en cahices y barchillas. 1 cahiz $=12$ barchillas).

(61) «Y lo (vi) ques troba es tan agre y ruhin que causa moltes enfermetats als cosos humans (...) com de dites coses consta ab informacio de doctors en medicina y persones expertes». AMO: Provisiones Reales 1523-1617, f. 57. El Virrey a la Ciudad (20-VII-1589).

(62) AMO: Provisiones Reales 1571-1688, f. 194. 
Sr Obispo. Un examen detenido de los individuos que vendían su trigo a la institución y las cantidades respectivas - desde principios de julio hasta finales de diciembre - revela quienes constituían el reducido grupo de beneficiarios (63).

Pero no toda la comercialización interior se realizaba a través del pósito, entre otras razones porque la tasación del precio que éste lo vendía no podía competir con el de mercado, sujeto a las fluctuaciones de la oferta y la demanda. El mecanismo era, a grandes rasgos, el siguiente: En época de la cosecha y meses posteriores el pósito se iba abasteciendo paulatinamente en cantidades fluctuantes, según las previsiones calculadas en razón de la cuantía de la cosecha, que influía a su vez en los precios de compra. Conforme se iba abasteciendo el pósito con dinero procedente del fondo constituido a tal efecto -estipulado por estatutos en 6.000 libras (64), hasta 1650 en que Centelles lo elevó a 10.000 (65) - , los panaderos quedaban obligados a tomarlo de él, pagando un sobreprecio de un sueldo por barchilla -que constituía la ganancia del pósito-, amasarlo y venderlo al común con una sobrecarga de 5 dineros por barchilla, que se embolsaban de beneficio.

Cuando la nueva cosecha estaba ya próxima y aún quedaban grandes cantidades almacenadas, con el consiguiente riesgo de perderse, el administrador del pósito tenía facultad para hacer repartición del trigo sobrante entre el vecindario a un precio nunca inferior al de compra. Esta situación, que debió presentarse muy a menudo dada la presión ejercida por ciertos cosecheros para asegurar su venta, planteaba graves problemas puesto que el precio corriente por la Ciudad era entonces más bajo que aquel al que pretendía repartirlo el pósito (66). Más aún, si la cosecha anterior no había sido deficitaria, el precio del grano fuera del pósito solía ser durante todo el año también inferior. Consecuencia de todo ello era que los panaderos no compraban del pósito sino de particulares y, aun cuando la administración consiguiera hacer forzosa su compra, el vecindario se negaba a acudir a las panaderías municipales, puesto que fuera de ella lo encontraba más barato. Algunos ejemplos pueden documentar ampliamente esta situación.

En 1646 - por lo tanto antes de la despoblación - la Ciudad ya mantuvo un pleito con los panaderos, pues éstos

(63) AMO: Contrallibre del Posit 1651, Contrallibre del Posit 1652 y Llibre del Posit 1655-56. Para 1654 no se poseen datos y 1653 fue un año de pésimas cosechas, habiéndose de importar trigo, por lo que los abastecedores del pósito era casi todos comerciantes y mercaderes forasteros.

(64) AMO: Recopilación..., f. 85. Las ganancias que excedieran de dicha cantidad habrían de destinarse al quitamiento de censales de la Ciudad.

(65) AMO: Ibidem, f. 85 v.

(66) AMO: Ibidem, ff. 81-92, donde se recogen todos los estatutos referentes al funcionamiento del pósito. Un breve y clarificador resumen en AMO: Contestador 1650, ff. 379 y ss. Memorial de la Ciudad al Virrey. 
«no solo se an contentado con no sacar el trigo que ai comprado en el posito pues para despues de San Juan (en que se avia de haver acabado de vender) quedaron mas de 400 caises de trigo que vender con evidente peligro de perderse, pero si algun particular a querido vender alguno se le an comprado por mucho menos de lo que corria» (67).

En 1649-50 la situación volvía a repetirse, al hallarse el pósito con 500 cahices, parte de los que la Ciudad había comprado el año anterior a 8 libras el cahiz. La mala cosecha de 1647 -en gran parte responsable de la enorme difusión de la epidemia - había encarecido el trigo, llegándose a vender a 15 y 16 libras el cahiz. La abundante cosecha de 1648 no impidió, sin embargo, que en un principio los precios subieran muy por encima de lo previsto, al ser exportado gran parte por cosecheros particulares hacia Murcia y Cartagena. Una vez desaparecida esta posibilidad, con la importación de trigo ultramarino por parte de Cartagena.

«volvio a baxar el precio, de tal manera que hallandose los vezinos con mucho trigo, para haverle de vender hubieron de baxarle a mucho menos precio, del que la Ciudad lo dava a los panaderos con que cada uno se provehia de trigo con comodidad, para gastar en su cassa, y assi los panaderos vendian poco pan y se sacaba muy poco trigo del Posito" $(68)$.

Los 500 cahices sobrantes fueron repartidos obligatoriamente entre el vecindario en junio de 1649 con la obligación de ser devueito una vez recogida la nueva cosecha con un interés de 1 barchilla por cahiz recibido. La cosecha de 1649 volvia de nuevo a ser abundante, por lo que el trigo recobrado por el pósito no pudo ser expedido. Las razones eran bastante explícitas:

«...porque como la cosecha sea grande y los vezinos pocos por haverse inuerto mas de la mitad de la Peste y esta toda la comarca llena de trigo y bacia de gente, ha venido a envilecerse el precio del trigo de tal manera, que apenas hay quien pague treynta reales por un cays, y como el precio a que costo a la Çiudad sea de ochenta reales muy pocos son los que van a comprar pan a la panaderia, si que por fuera ios compran los vezinos y moradores y se proveen para su susiento» (69).

Además, «aunque se les aga todas las extorciones posibles a los panaderos no sacaran nada ni le podran vender ni aura quien lo compre» (70).

Ante esta situación la Ciudad carecia de fuerza moral para obligar al pueblo a pagar precios excesivos, puesto que el trigo abundaba. La única salida era entonces solicitar del Virrey la dispensa del estatuto por el cual el

(67) AMO: Cortestador 1646, f. 315 v. Memorial de la Ciudad al Virrey (23-V-1646).

(68) AMO: Convestador 1650, ff. 379-379 v. Memorial de la Ciudad al Virrey. La situación volvió a repetirse en 1645. AMO: Contestador 1654, f. 282, La Ciudad al Regente (14-XI-1654).

(69) AMO: Contesiador 1650, f. 379 v.

(70) AMO: Ibidem, f. 310 v. La Ciudad al Dr. Bernardino (5-1I-1650). 
trigo repartido por el pósito había de cobrarse con una sobrecarga respecto al precio de compra, pues de no hacerse así «sería dar ocasión a que los vecinos tomaran las armas en las manos» (71).

En definitiva, los efectos que la existencia de una administración municipal de granos podía tener en una ciudad como Orihuela, normalmente sin graves problemas de aprovisionamiento, merced a las abundantes cosechas producidas en sus términos y la insuficiencia de población que la consumiera en su totalidad, eran dobles. Por un lado, asegurar la venta de gran parte de la producción de ciertos cosecheros en el mercado local; por otro, encarecer a través de vías institucionales el precio del producto que constituía la base del consumo popular. Pero si las condiciones reales de mercado acababan casi siempre imponiendo su ley en lo relativo a los precios del trigo, el severo intervencionismo municipal en la regulación salarial tampoco podía estar exento de incumplimientos por parte de los jornaleros agrícolas e incluso de los asalariados en otras ramas de la producción.

La coyuntura desatada a partir de 1648 , al reducir considerablemente la fuerza de trabajo - sobre todo teniendo en cuenta la mayor incidencia de la epidemia entre las clases bajas de la población- quedó reflejada en un importante incremento salarial, al tiempo que se reducían los precios de los productos agrícolas y artesanales. Al año siguiente los Jurados tomaban cartas en el asunto para

«...el reparo del abus de aver alterat en la present ciutat los preus a los
lavols los jornalers de ella y les obres macaniques les mestres de elles a
causa del mal contagios que en la present ciutat ya agut en lo any pa-
sat (...) i no averse puxat de preu los manteniments ni vitualles ans be
se an venut e venen en los mes inferiors preus que de molts anys a esta
part se a vist» (72).

Las intenciones eran «regularizar en son primer estat conforme lo es en lo any antesedent al contagi». Faenas agrícolas, actividades artesanales, transportes de diferentes productos, todo quedó regulado minuciosamente asignando a cada trabajo en particular un tope salarial máximo. La diferenciación se establecía no sólo entre las diversas ramas productivas, sino también para cada trabajo especifico y concreto, variaciones estacionales incluidas y discriminando a veces el trabajo femenino. Además de las penas en que incurrian sus infractores, se pretendía evitar la posible negativa del jornalero concediendo

«facultat a quealsevol persona que constant que li conste que al dit preu imposat no aura volgut anar a treballar i aquell dia folgara que puxa capturarlo o ferlo capturar».

Pese a todas estas disposiciones, de dudosa observancia real, parece ser que los salarios no volvieron ya a la situación anterior a 1648 , como de-

(71) AMO: Ibidem, f. 364 v. El Dr. Bernardino a la Ciudad (17-11-1650).

(72) AMO: Contestador 1649, fí. 41-44. Crida. 
seaba el gobierno de la Ciudad. A los mondadores, por ejemplo, se les estipuló un salario de 8 sueldos y 9 dineros diarios, al tiempo que se recordaba cómo con anterioridad a dicho año se les pagaba 6 sueldos. Pero si la tasación de 1649 dejaba de corresponderse con los salarios vigentes antes de la epidemia, la desigual correlación de fuerzas entre la oferta y la demanda en el mercado de trabajo determinó que los jornaleros incumplieran frecuentemente dichas disposiciones ante la impotencia de los productores que los requerían. Al menos esto es lo que parece desprenderse al comparar los salarios oficiales con los realmente pagados por el Colegio de Predicadores de Orihuela por ciertos trabajos agrícolas. Así, dicha institución pagaba por podar sus parras 8 sueldos en 1649,1650 y 1652, 9 sueldos en 1651 y 1655 , y sólo en 1654 llegó a pagar 7 (73), cuando la tasación de 1649 prohibía hacerlo por encima de los 6 o los 7 sizidos, según se tratara de los meses anteriores o posteriores a Navidad.

En 1652 los mondadores cobraban ya 14 sueldos por lo que nuevamente hubo de intervenir el gobierno municipal (74). Pero la nueva regulación ya no podía volver siquiera a restablecer la tasación de 1649 . La realidad era demasiado evidente como para intentar ingnorarla. Pese a ello el salario quedó estipulado en 10, 11 ó 12 sueldos - según estaciones-, al tiempo que se fijaba la jornada laboral de sol a sol (75). También para los albañiles quedaron establecidas en dicho año sus horas de trabajo y sus nuevas percepciones y derechos (76).

La situación de la fuerza de trabajo parece ser, por tanto, que debió quedar sensiblemente mejorada tras el desastre demográfico, pese al intervencionismo municipal empeñado en favorecer a la oligarquía de propietarios

"porque el año menesteroso, no sólo la gente de la tierra trabaxa, pero acuden muchos forasteros a lo mesmo, i por qualquier jornal se acomodan, pero en año abundante piden lo que quieren, porque con un jornal tienen pan para una semana, i si se les da poco no trabaxan, si no es pagandoles lo que quieren" (77).

Los intereses de la élite dirigente estaban bastante claros en relación con la explotación agraria. Unos intereses que sufrieron las negativas consecuencias de la peste de 1648 y que, para hacer mínimamente rentable la explotación de sus haciendas, motivaron una actuación encaminada fundamentalmente a

(73) AHO: Liber expensarum huius Colegii.

(74) AMO: Contestador 1652, ff. 179-179 v. Crida.

(75) «...que ajem de comensar a treballar en estar clar el dia fins que escureixca». AMO: Ibidem.

(76) Aparte del jornal en metálico había de dárseles media cuarta de vino y al maestro, además, pan para el almuerzo. AMO: Ibidem.

(77) AMO: Provisiones Reales 1571-1688. f. 196. Memorial al Dr. Salazar. 
a) reducir los costes de producción mediante la regulación salarial, esto es, a través de vías institucionaies, y

b) asegurar la comerciaiización de las cosechas al nayor precio posible.

Fara ello se utilizaron los mevanismos disponibies, pero dicha intertvención quedaría ampliamente desbordada por las condiciones reales de mercado. Pero la oligarquia municipal no lograba rentabilizar adecuadamente sus haciendas si restringía su horizonte económico ai mercado local. Por tanto, paralelamente a la actuación desarrollada en este sentiơ, intentaba al mismo tiempo la obtención de optimas condiciones para la exportación de los excedentes, lo que habría de vincularia de alguna forma a la clase de mercaderes.

\section{INTENTOS PARA HACER NAVEGABLE EL SEGURA Y CONSTRUIR UN PUERTO EIN LA COSTA}

Como último recurso, por el costo que suponia su realizacion, el Jurado en cap del estamento militar proponía en 1655 al Consejo hacer navegable el río Segura desde la ciudad de Orihuela hasta su desembocadura en Guardamar (78). La idea no era nueva en sí, pnesto que er 1584 la ciudad de Murcia ya había pretendido lo mismo, sin que se llevara a cabo (79), como tampoco fue posible la obra concebida para el Tajo desde Toledo a Lisboa (80). El Consejo de Orihuela, lógicamente, aceptó el proyecto que, posteriormente, sería rechazado por los ingenieros encargados de su realización, tras un informe donde se daba cuenta de su improcedencia. Lo interesante del memorial presentado para la aprobación del Consejo radica en que, una vez más, salían a resurgir los objetivos que se perseguian, ai tiempo que ofrece una interesante información sobre la situación de İa agricultura. Ya en el encabezamiento se haciía referencia, ccmo justificación de la propuesta, a la miseria en que había quedado sumida la Ciudad como consecuencia

«de no tener salida ni despacho en los frutos que recogen en su ferti! guerta y campo. Desdicha es esia de las mayores que se pueden considerar pues quando todas las provincias se enriquecen reniencio abundancia de cosechas y frutos esta se empoorese quando les tient pues es causa de que los jornaleros no quieren trabajar por tener asegurado s' sustento con mui poca cantidad y si trabajain no tienen los dueños de las hacienas con que pagarles por no allar quien les conpre los frutos que an coxido por lo que se dexa de acudir a lo mui forçoso y las ha-

(78) AMiO: Coniestador 1655, ff. 192-197 v. Ajust de Consell de 22-ĩx-1655.

(79) F. CHACON PEREZ: Murcia en la Cerituria del Cuinientos, Acaciemia Alionso el Sabic, Murcia, 1973 , p. 61.

(80) A. DOMINGUEZ ORTIZ: El Anưguo Régimen: Les Keyes Caśblicos y les Ausurias, Alianza Universidad, Niadrid, 1973, p. 89. 
ciendas se an perdido la mayor parte y las demas se estan perdiendo a toda diligencia».

Y tras manifestar que «haciendo nuestro río navegable pues será occacion de que en la Ciudad haia mas concurso de gente que consuma los frutos que se coxen en ella que saquen los que no huvieremos menester y nos traigan por mar los que nos faitaren», se enunciaban y analizaban las ventajas que ocasionaria dicha obra:

a) Se activarían las relaciones comerciales con Castilla. La habilitación del transporte fluvial, dado el ahorro que suponía con respecto al terrestre - «...pues ya se sabe que los hombres de negocios procuran el ahoro de las mercancías por mínimo que sea»- atraería las lanas castellanas con destino a ultramar que, de este modo, serían embarcadas en Orihuela por su cercanía al vecino Reino. Al mismo tiempo, y por idénticas razones, se traería ia pesca necesaria para el consumo de Castilla. Además, los navíos se sentirían atraídos a desembarcar en el Río, al poder abastecerse de agua y lefia sin coste alguno y de sal de las Salinas de la Mata, cada su cercanía. Todo lo cual redundaría en beneficio de los hombres de negocios locales «porque el despacho de la pesca y de otras mercaderías a de ser por comission cossa que a echo ricas muchas cassas en otras partes y en que se acomodaran muchos vezinos de esta Ciudad».

b) Las felices repercusiones de este tráfico comercial sobre ỉa Ciudad consistiría en que «en esto se utila mucho concurso de gente que consumiran parte de los frutos y que por no volverse de basio nos compraran los frutos que tenemosi. ¿Cuáles eran tales productos que se esperaban exportar?;

«barrilla, sosa, trigo, sevada, aseite, vino, esparto, avas, garvanços, arros, miel, passas, higos, y almendras y vinagre; y otros frutos de que abunda nuestra tierra mas que otras y la gente se dara a benefiçiar la regalicia, vinagre y biscocho y otras cossas que hasta oy no nos utilamos dellas por no averlas entendido, o por no aver tenido modo de despacho pues la Ciudad de Alicante aun no nos a permitido embarcar en su mueille vino de nuestra cosecha».

c) Por último el Real Patrimonio obtendría también su beneficio al incrementar sus percepciones por derechos aduaneros, al tiempo que se evitarían los fraudes del contrabando marítimo con sólo poner dos guardias de vigilancia «pues sabemos que en nuestra costa se embarcan mucha parte de estos frutos sin pagar drecho alguno».

Acto seguido se reconocían las dificultades financieras de la operación, por el enorme gasto que podría suponer para una Ciudad permanentemente endeudada y en sitıación de franca bancarrota, pero el optimismo en razón de las ventajas que se seguirían de su realización, hacía exclamar: «pongamos los ojos en nuestra miseria y en que no podemos vivir con lo que tenernos que la nessesidad nos alertara a que resistamos qualesquier gasto que nos puedan sobrevenir». 
Finalmente, y como complemento de lo anterior, se proponía la construcción de un puerto marítimo dentro del término de la Ciudad. Una vez escuchada la propuesta por el Consejo, se votó a favor por unanimidad, encargándose una comisión de gestionar las instancias pertinentes para la obtención de las licencias necesarias y de la búsqueda de técnicos que dictaminaran sobre su viabilidad.

En resumidas cuentas, se trataba de avivar las actividades comerciales, sobre todo de cara a la exportación de las cosechas no consumidas en la Ciudad, mediante la creación de una infraestructura viaria y portuaria que permitiera un ahorro en los costes de transporte, una estabilidad en las relaciones comerciales por vía marítima desde las costas de Orihuela que ya eran mantenidas desde tiempos atrás pese a la oposición de la ciudad de Alicante en sus intentos por monopolizar tales actividades.

En 1643, por ejemplo, el Síndico alicantino llegaba a Orihuela con un mandato de la Real Audiencia prohibiendo el embarco y desembarco de mercancías en las costas del término oriolano. Inmediatamente se dieron las órdenes oportunas al Síndico de Orihuela en Valencia para que intentase la confirmación de una provisión de firma de derecho obtenida ya ante el Gobernador de la Ciudad (81). Pese a que la ciudad de Orihuela tenía privilegio de embarco y desembarco en su ribera marítima -en el puerto llamado Cap Cerver- otorgado por Alfonso X en 1303 y confirmado posteriormente por distintos monarcas en 1309, 1313, 1547 y 1604 (82) -, el Síndico en Valencia recibió instrucciones de actuar con la máxima cautela y precaución.

«Y que es faça diligencia de que es proveixca en la Sala del Dr. Guinart, y no en la que estan los DD Sanchiz y Mingot per ser apasionats per Alacant lo hu per ser natural de aquella, y lo altre per ser son gendre de Alacant y procurar la provisio de manutenencia ab tot secret ans que se entenga per lo de la altra Sala» (83).

La defensa de estos asuntos constituía una cuestión de vital importancia para la ciudad de Orihuela aun antes de la epidemia (84), pues no sólo estaban en juego los intereses de los cosecheros locales, sino también los de ciertos mercaderes a comisión que intervenían en el comercio con Castilla a

(81) AMO: Contestador 1644, f. 334 v. La Ciudad al Dr. Claudio Bertina (5-V-1643).

(82) AMO: Contestador 1646, f. 312. Memorial de la Ciudad al Rey. El privilegio de Alfonso $\mathrm{X}$ fue dado en Carmona a 25-VIII-1303 y ratificado en Murcia a 20-VII-1309. El de Jaime II fue firmado en Valencia a 10-II-1313; el de Felipe II en Monzón, a 18-XI-1547, y el de Felipe III en Alcalá, a 7-III-1604.

(83) AMO: Contestador 1644, f. 335 v. Instrucciones de la Ciudad para el Dr. Claudio Bertina (5-V-1643).

(84) «Esta causa Sr. es la que esta ciudad puede tener de más consideración, y la que a de defender aunque se gaste todas sus rentas». AMO: Ibidem, f. $334 \mathrm{v}$. 
través de Murcia (85). La oposición de Alicante debió, no obstantee, obstaculizar las gestiones realizadas por Orihuela que, en 1646, volvía de nuevo a manifestar sus pretensiones. Esta vez se trataba de obtener licencias para la construcción de un puerto que «gose de las mesmas inmunidades y gracias de que gosaba el de cabo cerver» (86), al no haber podido conservarse este último "por averse retirado el mar». Entre los argumentos de la Ciudad se hacía constar que «todo el esparto que se embarca para el marinatge se coge en aquella tierra y por averse de llevar a Alicante a vender cuesta muy mas caro». Pero además, de esta forma «...se evitaran los fraudes que se causan a los drechos reales pues por distar la ciudad de Cartagena de la de Alicante quinse leguas de costa no solo se desembarcan muchas mercansias sin pagar drechos pero tambien urtan mucha sal de la que V. Magd. saca de dichas salinas».

Obviamente, no podían faltar manifestaciones de este tipo mediante las cuales se trataba de hacer comprender a la Corona los beneficios que el Real Patrimonio podía obtener de ello, pero no era esto lo que impulsaba a la Ciudad a emprender una obra tan costosa, sino la consideración de que de este modo «...prevenimos modo de vivir extraordinario». Trece años más tarde -en 1649- aún proseguían las gestiones en Valencia y Madrid (87), sin que Orihuela obtuviera nunca licencia a favor (88). El proyecto de 1655 acerca del Río constituía, pues, un intento más de buscar solución a los problemas de comercialización, agravados por una coyuntura que había reducido considerablemente el consumo local. Es por ello que el nuevo intento fuera más ambicioso, incluyendo la posibilidad de contactar directamente con el mar a través de una vía fluvial, con todas las ventajas que este tipo de transporte conllevaba sobre el terrestre.

Votado el proyecto en el Consejo por unanimidad, se nombraron electos para que tratasen de «procurar perçones expertes axi estrangeres com

(85) De no tener contırmación en sus derechos, uno de los perjuicios consistiria en que «distando Castilla sólo una legua desta Ciudad, no allando aqui paraxe ni desembarcación se pasan a Castilla donde a su salvo pueden haser lo que les convenga». AMO: Ibidem.

(86) AMO: Contestador 1646, f. 312 v. Memorial de la Ciudad al Rey. El puerto de Cap Cerver era el punto de embarque tradicional de las salinas de La Mata y a través de él se realizaban importantes transacciones comerciales. Según Bellot, hacia 1400 «tenían los de Orihuela muchos géneros de navíos, como son carabelas, panfilos, bolanares, fustas, galeotes y barcas, con las quales unos trataban y otros iban en corso». M. P. BELLOT: Anales de Orihuela (siglos XIV-XVI). II, Orihuela, 1959, p. 34.

(87) En carta al Síndico, la Ciudad avisaba «que el memorial de puerto es menester llevarlo con prudencia y cautela y que la Ciudad de Alicante no lo entienda». AMO: Contestador 1649, f. 543. La Ciudad a Pedro Juan Ferrer (2-VIII-1649).

(88) También por estas fechas (1645-48) el Señor de Elche mantenía un pleito con dicha villa por la posesión del puerto de Aljup de Santa Pola, pretendiendo su habilitación para la comercialización de todo tipo de mercaderías - como el de Alicanie-y no sólo para los frutos del marquesado. Vid. EVA SERRA Y PUIG: «Notes per a una aproximació a l'estudi del règim senyoral al País Valencià al segle XVII», Primer Congreso de Historia del Pais Valenciano, vol. III, Valencia, 197 , p. 359. 
altres qualsevols, los quals regoneguen el Riu y el siti mes a proposit per a el port» e hiciesen las diligencias legales oportunas. El trabajo de reconocimiento fue encomendado finalmente a Joan Batiste Balfago, ingeniero de la ciudad de Cartagena -que por aquellos días se encontraba en Murcia (89)- quien, junto con su hijo y Melchor Valls, asimismo ingenieros y arquitectos, recorrieron el Segura desde Orihuela hasta su desembocadura en la gola de Guardamar. Una vez allí habrían de reconocer la costa hacia el sur hasta la Torre de Cap Roig con tal de buscar el lugar más adecuado para la construcción del puerto (90). De resultas de la inspección los técnicos elaboraron un informe dando cuenta de las conclusiones a que habían llegado (91).

El primer obstáculo a superar era la presa de Alfaitami, en el término de la Universidad de Almoradí. Los 12 palmos de desnivel que allí alcanzaban las aguas podían ser contrarrestados mediante la construcción de un dique de 70 palmos de largo con dos paradas, lo que se estimó costaría 2.000 ducados. Dos nuevas presas, la de Rojales y la de Guardamar, tampoco constituían inconvenientes insuperables mediante la realización de las obras oportunas, cuyos costes podrían ascender a 2.000 y 1.000 ducados respectivamente.

El grave problema, que determinaría la inviabilidad técnica del proyecto - informados por los barqueros de Guardamar - se encontraba, sin embargo, en la desembocadura del Río, por estar la gola sujeta a constantes variaciones derivadas de los depósitos arrastrados en las crecidas y de los vientos de levante, que acumulaban la arena «...de suerte que no tiene despedida el agua». Y aunque esto pudiera remediarse con la construcción de una estacada, sería «obra incierta y no pueden asigurar si haziendola se evitara el cegarse la dicha gola del rio, o no». Pero además, dado el régimen fluvial del Segura, en épocas de crecida serían necesarios más de $4 \mathrm{ca}$ ballos para remontar una carga de 500 quintales en un día, mientras que durante el verano su bajo caudal haría imposible su navegación.

El proyecto en cuestión fue, por tanto, rechazado por motivos en gran parte derivados de las condiciones hidrográficas del Segura, junto a la imposibilidad técnica - dados los conocimientos de la época- para vencer tales dificultades. Muy diferente fue, sin embargo, el informe relativo a la construcción del puerto.

Rechazada la propuesta de hacer muelle en Guardamar por ser término independiente de Orihuela, y en Cabo Roig porque la excesiva profundidad del agua encarecería sobremanera la obra, se determinó finalmente co-

(89) AMO: Contestador 1655, f. 9 v. Provisio dels Jurats (24-II-1655).

(90) AMO: Ibidem, f. 198 v. Ajust de Consell (16-III-1655).

(91) AMO: Ibidem, ff. 199-200 v. «Relacio echa por los Elets del Consexo sobre la navegación del Río». 
mo lugar más apropiado para su construcción la llamada Torre Viexa. Las condiciones allí eran óptimas: agua suficiente para permitir el fondeo de los bajeles grandes, bahía abrigada de los vientos, etc. Por razones de seguridad frente a las eventuales incursiones piráticas, la construcción del muelle debería ir acompañada por la de «un fuerte Real con cuatro baluartes que tenga dentro treinta y dos cassas, iglesia, cassa del Alcayde, dos Almasenes, y algibes con agua bastante, i artilleria para los baluartes»; lo que costaría veinte mil ducados, más dos mil de la obra del puerto. Pero aún quedaba por resolver el problema de los permisos necesarios, a lo que se oponía la ciudad de Alicante.

No obstante, Orihuela no estaba đispuesta a renunciar fácilmente a sus pretensiones. El dictamen negativo sobre el Río no debió tener plena aceptación en el Consejo, puesto que en septiembre del mismo año se enviaba un embajador a Madrid con instrucciones muy concretas: «buscar aigun extranjero que sea entendido para hazer ei riu navegable como lo son en Italia» (92). Al mismo tiempo se encomendaba hacer lo posible para que, en caso que esto no tuviese efecto y se denegaran las licencias necesarias para el puerto, se obtuvieran al menos dos mercedes reales. Una de ellas solicitaba que la ciudad de Valencia se comprometiera a comprar anualmente 8.000 cahíces de trigo a Orihuela «...y esto en el caso que la Ciudad tenga comodidad de venderle, y de suerte que no podamos ser apremiados a darle pero que Valencia lo este para recibirle». La segunda pedía que nadie pudiese poner impedimento para que, pagando los derechos correspondientes, Orihuela pudiese embarcar en Alicante o en cualquier otra parte 20.000 cántaros de vino cada año «y todo el arroz y panes menudos que le convengan».

Efectivamente, ni las obras del Río ni la construcción del puerto se llevaron a efecto y nada sabemos sobre las otras dos pretensiones. En 1700 la Ciudad volvería de nuevo a la carga con argumentos similares para obtener la licencia del puerto (93).

\section{ALGUNAS CONSIDERACIONES FINALES}

Aquí se ha pretendido mostrar, en primer lugar, cómo en una ciudad valenciana del Seiscientos las reglamentaciones municipales podían se utilizadas por el grupo que detentaba el poder, dada la amplia capacidad autonómica que el régimen foral ponía en sus manos. Un grupo de poder constituido íntegramente por una oligarquía de Caballeros y Ciudadanos y ex-

(92) AMO: Contestador 1656, f. 348 v. Instrucciones de la Ciudad para el Dr. Pedro Díaz de Saiazar.

(93) AMO: Contesíador 1700, ff. 206-210 v. «Representación práctica que haze la Ciudad de Orihuela a su Mgd. por la pretención del Embarco y Desembarco». Debo la referencia a la gentileza de Jesús Millán. 
cluyente de todo aquel que no participara de esta condición. Pero tampoco se ha de caer en el error de considerarlo como un bloque monolítico en función, más que nada, de la presencia de posibles rivalidades internas de orden secundario traducida en lucha de facciones que en última instancia, nunca llegarian a cuestionar el sistema como tal.

Hemos prescindido de analizar la dinámica interna de esta élite dirigente, mediante el estudio de las relaciones que mantenían entre sí, así como de las que les vinculaban a la Nobleza superior y, por otra parte, con los individuos que intentaban engrosar sus filas a través de mecanismos diversos de promoción social. Todo lo cual resultaría bastante revelador de cara a precisar el contenido exacto de la composición y articulación real de los grupos de poder fáctico y de las posibilidades de participación que ofrecía a los distintos miembros del conjunto social.

Pero un hecho parece desprenderse claramente de la documentación consultada: tanto los Jurados como el Consejo apelarán constantemente a la defensa de los fueros, privilegios y libertades que el régimen foral les atribuía ante el menor indicio de que se pudiera atentar contra ellos desde el poder central -encarnado bien en la Corte Real, bien en Valencia-e incluso desde ciudades regnícolas vecinas. $\mathrm{Y}$ táles intromisiones eran enérgicamente protestadas por la Ciudad en la medida en que coartaban o intervenían su autonomía y capacidad de control municipal (94). Lo cual no excluye una cierta demagogia implícita en la adopción de actitudes paternalistas sobre la comunidad.

El control del poder era, en consecuencia, una fuente nada despreciable de enriquecimiento, a través de la corrupción administrativa o de su utilización para la salvaguarda de los propios intereses. Cuando esta función era cuestionada por circunstancias coyunturales adversas - provocadas en gran medida por un abuso desmedido- decaía el interés por la participación directa en los órganos de la administración. Pero en modo alguno cabe pensar en una explícita voluntad colectiva de renuncia, reacción, de otra parte, tan suicida como inviable y que hubiera supuesto la inclusión de ele-

(94) A título de ejemplo hemos de señalar las instancias realizadas por Orihuela en 1656 ante el Consejo de Aragón y Felipe IV en defensa de las prerrogativas de su Tribunal de Gobernación, usurpadas por la Real Audiencia de Valencia. El problema había surgido cuancio 15 de los prohombres de la Ciudad -entre ellos algunos Nobles- habían sido apresados y llevados a Valencia. (AMO: Contestador 1656, ff. 348, 372-373 v, 374-374 v. Incluso se pidióo al Rey la celebración de Cortes Generales del Reino, donde se garantizara el respeto a los fueros (Ibidem, ff. $370 \mathrm{v}$-371), hecho probablemente relacionado con los inicios de la reacción foral. Vid. L. J. GUIA MARIN: Op. cit. pp. 129145. También en 1646 mantuvo Orihuela pleito con Alicante, que pretendía dividir la Gobernación (AMO: Contestador 1646, ff. 269-269 v, 306-306 v...). Por otro iado, tampoco faltaban incidentes entre los Jurados y el Lugarteniente del Gobernador (Ibidem, f. 314 v; Contestador 1651, f. 387; Contestador 1654, ff. 268 v-269) o su Subrogado (Contestador 1652, ff. 351 v, 357 v-358 v) e incluso con el Bayle General de Orihuela (Contestador 1649, ff. 510 v-511; Contestador 1651, ff. 384-384 v). 
mentos exógenos en el grupo de poder, lo que ni remotamente se planteaba la oligarquía. Podía, eso sí, pedirse la participación de la Nobleza, pero su influencia real en la vida política y económica municipal debía ser ya, de hecho - como la de la Iglesia-, bastante ostensible como para pretender ignorarla.

Por otra parte, se ha afirmado la vinculación de la oligarquía a los intereses agrarios, puesto que la propiedad de la tierra constituía la base fundamental de su riqueza y prestigio, máxime en una coyuntura en que la catástrofe financiera dificultaba enormemente la rentabilidad de la otra fuente de ingresos. La crisis de proauctividad y los problemas de comercialización de los excedentes, agravados por la despoblación que siguió a la epidemia de 1648 al reducir el consumo interno, podía atentar directamente contra los fundamentos mismos de su base económica si no se tomaban las medidas adecuadas. Y la actuación desarrollada en este sentido creemos que ha quedado suficientemente clara. Ello no invalida, obviamente, que otros grupos sociales, tales como grandes cosecheros aún plebeyos y comerciantes, pudieran resultar asimismo favorecidos.

Respecto a los cosecheros, sus objetivos económicos no podían ser más comunes a los defendidos por la pequeña nobleza, a cuyo status social muchos debían aspirar. Algo distinto debía ocurrir con los comerciantes, cuyos intereses objetivos e históricos debían ser opuestos al intervencionismo municipal en la medida en que obstaculizaba la libre concurrencia en el mercado; pero la oligarquía necesitaba de ellos para la exportación de sus cosechas, por lo que una cierta alianza entre ambos era tan aconsejable como inevitable. El papel del capitalismo comercial en toda esta trama de relaciones podía ser ambivalente. Por un lado los comerciantes eran solicitados por los cosecheros pero, al mismo tiempo, sus actividades no estaban completamente liberalizadas pues, en última instancia, dependian de las decisiones municipales. Su condición de subordinados a disposiciones ajenas, que no controlaban en absoiuto, limitaba decisivamente sus posibilidades de expansión. Pero no hay que olvidar los intereses de los propietarios en mantener esta clase de comerciantes y, en sus intentos aquí estudiados, se contaba explicitamente con ellos.

Finaimente, el intervencionismo municipal reflejado en la regulación de precios no actuaba, contrariamente a lo que se ha observado en otros ámbitos, como una mera arma contra los vendedores de granos (95), por la sencilla razón de que los encargados de dictaminar tales medidas eran los propios cosecheros y, además, se contaba con excedentes suficientes. El paternalismo explícito en la fijación de precios máximos afectaba, pues, a aquellos artículos cuya producción era ajena a la base económica de la pequeña nobleza. Lo que era perfectamente consecuente tratándose de una

(95) Cf. M. DOBB: Estudios sobre el desarrollo del capitalismo, Madrid, Siglo XXI, 1976, pp. 117-118. 
ciudad típicamente ruralizada, donde poder y propiedad de la tierra iban estrechamente vinculados.

El papel que el régimen foral desempeñó en la transición al capitalismo es una cuestión que habría que estudiar muy detenidamente y sobre la que, por el momento, no podemos plantear hipótesis. Aquí se han expuesto algunos datos a tener en cuenta y se ha intentado suscitar algunos problemas, dado lo limitado de la parcela y la temática investigada. 